\title{
A QUALIDADE E ENSINO DE GRADUAÇÃO E O COMPLEXO EXERCÍCIO DE PROPOR INDICADORES: É POSSÍVEL OBTER AVANÇOS?
}

\author{
Maria Isabel da CunHA*
}

Recebido: 5 mar. 2014

Aprovado: 30 maio 2014

* Universidade do Vale do Rio dos Sinos. São Leopoldo, RS, Brasil. E-mail:cunhami@uol.com.br

Resumo: O texto se insere nas reflexões sobre os indicadores de qualidade da educação superior e decorre de um projeto de pesquisa desenvolvido no Observatório da Educação Superior MEC/CAPES/INEP/ RIES. Parte do conceito de qualidade da educação explicitado na LDB/96 como um referente e, no caso da universidade, toma o dispositivo constitucional da indissociabilidade do ensino, pesquisa e extensão como a expressão que orienta a qualidade da educação superior. Reconhece o conceito de qualidade como multireferenciado, dependente de contextos, culturas e ideologias. Assume que a organização de indicadores de qualidade dos cursos e instituições tem sido um grande desafio quando deseja afastar-se das formulações generalizadoras. Propondo-se a um exercício dessa natureza, a autora coordena um estudo de organização de indicadores de qualidade do ensino de graduação, a partir de um instrumento de pesquisa aplicado a docentes e estudantes universitários. Com os resultados organiza duas famílias de indicadores, uma referenciada em produtos e outra em processos. Reconhece a limitação de exercícios dessa natureza, mas acredita ser importante a sua realização para orientar a direção dos processos pedagógicos que cada instituição, cursos ou comunidades de práticas deseja para si.

Palavras-chave: Universidade. Indicadores de qualidade. Ensino de graduação .

\section{QUALITY, UNDERGRADUATE TEACHING AND THE COMPLEX EXERCISE OF PROPOSING INDICATORS: IS IT POSSIBLE TO MOVE FORWARD?}

Abstract: This text integrates reflections about the indicators of quality in higher education and derives from a research project developed in the Higher Education Observatory MEC/CAPES/INEP/RIES. Its starting point is the concept of quality in higher education spelled out in LDB/96 as a referent and, considering the university, takes the constitutional provision of indissociability among teaching, research and extension as the expression that directs the quality of higher education. It acknowledges the concept of quality as multi-referenced and dependent of contexts, cultures and ideologies. It takes on that the organization of quality indicators in courses and institutions has been a major challenge when one wishes to move away from generalizing formulations. Willing to undertake an exercise of such nature, the author coordinates a study on the organization of quality indicators in undergraduate courses, based on a research instrument applied to university teachers and students. Based on the results, two families of indicators are organized: one referred in products and the other in processes. The author acknowledges the limits of exercises of this nature, but nonetheless believes they are important to guide the direction of the pedagogical processes that each institution, course or community of practices wishes to undertake.

Key words: University. Quality indicators. Undergraduate teaching. 
Para iluminar a reflexão sobre a qualidade do ensino de graduação e dos possíveis indicadores que facilitem a orientação da sua avaliação, procuramos olhar o fenômeno através de um viés cultural, ou seja, aquele que contextualiza o cotidiano de nossas práticas acadêmicas e os discursos nela produzidos. Não há dúvida que o conceito de qualidade sofre o impacto da regulação decorrente das políticas educacionais e da representação da sociedade, com especial destaque ao que se manifesta nos meios de comunicação social. Entretanto, é preciso destacar que a cultura acadêmica é também, um importante fator que determina compreensões da qualidade do ensino de graduação. As palavras de Milton Santos revelam essa condição:

A tirania da informação não é apenas da mídia, porque inclui, também, o nosso trabalho na universidade. Quero insistir, nessa tecla, porque o nosso trabalho como professores é a base com a qual se educam e se re-educam as gerações. Quanto mais o nosso trabalho for livre, mais educaremos para a cidadania. Quanto mais o nosso trabalho for acorrentado, mais estaremos produzindo individualidades débeis. É urgente que o ensino tome consciência dessa situação, para esboçar a merecida reação, sem o qual corremos o grande risco de ficar cada vez mais distante da busca ideal da verdade $(2000$, p. 76$)$

Essas considerações são estimuladoras porque no âmbito das reflexões sobre a educação superior, ouvimos freqüentemente as expressões "para uma educação de qualidade" e/ou "uma instituição de ensino por excelência". Essas expressões parecem abarcar inúmeras categorias, intenções, desejos, crenças, que dispensam explicações. Falar em educação de qualidade parece não precisar de complemento, pois o termo "qualidade" assim como "excelência", aponta para o máximo, para o melhor. Uma expressão incomparável onde qualquer definição se mostraria mais restrita do que a intenção do próprio termo.

Entretanto, o conceito de qualidade é multidimensional, o que torna complexo definir seu significado. Sua compreensão incorpora uma dimensão ética e estética e, principalmente uma dimensão axiológica. Rios (2001) chama a atenção para o fato de que o termo qualidade já carrega uma idéia de algo bom, contrapondo-se a noção de defeitos, incompletudes (p. 68). Entretanto, pela definição etimológica essa condição não tem sustentação. Qualidade não é uma adjetivação que remete a um construto universal, mas são propriedades que se encontram nos seres, ações ou nos objetos Ao atribuir qualidade a algo ou a um fenômeno estamos explicitando um valor, assim como quando dizemos que algo é belo ou adequado. Há, nessas expressões, uma concepção anterior que assume uma condição valorativa e que está ligada ao plano da moral e 
da condição política do homem. Essa perspectiva significa que a qualidade é auto-referenciada; pressupõe um sujeito ou uma comunidade que aceita determinados padrões como desejáveis. Para que se possa definir qualidade, é preciso que primeiro explicitar o sentido da ação e a dimensão sobre a qual se estabelece sua intencionalidade.

Ao pontuar estas ideias queremos chamar a atenção para o desfio de propor indicadores de qualidade em um âmbito mais alargado do sistema educacional. Mesmo com esse reconhecimento e considerando os limites desse exercício, tentamos levantar dimensões que vêm sendo legitimadas no campo da cultura e das políticas educacionais.

\section{LEGISLAÇÃO EDUCACIONAL NO BRASIL E QUALIDADE}

A Lei de Diretrizes e Bases para a Educação Nacional, em seu TÍTULO II - Dos Princípios e Fins da Educação Nacional, em seu Art. $3^{\circ}$, parágrafo IX diz que a educação deve garantir o padrão de qualidade, indicando uma preocupação de que esse atributo acompanhe a oferta dos serviços educacionais. Entretanto não define claramente o que seria o padrão de qualidade, ainda que seus dispositivos apontem desdobramentos que revelam concepções e valores.

A LDBEN (2001, p. 27) referindo-se ao Ensino Superior no CAPÍTULO IV - Da Educação Superior, em seu Art.43으, em vários parágrafos, explicita com mais clareza o entendimento de qualidade, através da caracterização de compromissos desse nível de ensino. Na Lei está explicitado que

a educação superior tem por finalidade, estimular a criação cultural e o desenvolvimento do espírito científico e do pensamento reflexivo; formar diplomados aptos para inserção em setores profissionais e para a participação no desenvolvimento da sociedade brasileira, e colaborar na sua formação contínua; incentivar a pesquisa e investigação científica, visando o desenvolvimento da ciência e da tecnologia, difusão da cultura, para desenvolver o entendimento do homem e do meio em que vive; promover a divulgação de conhecimentos culturais, científicos e técnicos que constituem patrimônio da humanidade e comunicar o saber através do ensino, de publicações ou de outras formas de comunicação; suscitar o desejo permanente de aperfeiçoamento cultural e profissional e possibilitar a correspondente concretização, integrando os conhecimentos que vão sendo adquiridos numa estrutura intelectual sistematizadora de conhecimento de cada geração; estimular o conhecimento dos problemas do mundo presente, em particular os nacionais e regionais, prestar serviços especializados à comunidade e estabelecer com esta relação de reciprocidade; promover a extensão, 
aberta à participação, visando à difusão das conquistas e benefícios resultantes da criação cultural e da pesquisa científica e tecnológica geradas da instituição (p. 27)

Depreende-se, dessas proposições uma posição em favor do estímulo ao poder de criação cultural do aluno, bem como para desenvolver o espírito crítico e o pensamento reflexivo. Mesmo tendo méritos nessa explicitação, os indicadores de qualidade apresentam grande complexidade, dificultando o direcionamento de políticas de fomento e avaliação que dêem sustentação aos processos a serem implementados. Envolvem condições subjetivas e, ao mesmo tempo, assumem positivamente a complexidade do processo educativo, reconhecendo a multiplicidade de fatores envolvidos no mesmo. Entretanto, favorecendo que a definição de padrões fique sujeita a lógicas políticas e econômicas conjunturais.

Estar apto a inserir-se profissionalmente constitui-se em um dos pontos importantes para definir a qualidade da formação dos alunos de graduação, na educação superior. Espera-se que o estudante saia da universidade com as condições básicas para o exercício profissional e as habilidades intelectuais e emocionais fundamentais para continuar aprendendo por toda a vida. Mas espera-se, também, que a as condições de exercício da cidadania balizem a sua formação.

A LDB dispõe, ainda, que a qualidade da educação superior seria a condição básica de credenciamento de uma instituição pelo Ministério de Educação. Nesse caso a qualidade é dimensionada por alguns fatores, especialmente os que envolvem o corpo docente, a infra-estrutura e a proposta curricular. A avaliação processual da instituição ou curso, entretanto, leva em conta o movimento que se dá no percurso de formação na sua relação com os resultados obtidos. ${ }^{1}$

Para chegarmos a uma educação de qualidade certamente será necessário alcançar um ensino de qualidade, uma gestão institucional de qualidade. Também ter professores formados com qualidade, que sejam capazes de realizar uma formação, também, de qualidade. È preciso que o educando tenha condições sociais que lhe permita uma aprendizagem de qualidade, que os cursos ofereçam espaços, materiais e equipamentos para que o processo de ensinagem ${ }^{2}$ ocorra com qualidade. Portanto a qualidade exige uma ação interligada em que as

1 Desde 2003, após a promulgação da Lei que definiu o Sistema Nacional de Avaliação da Educação Superior - SINAES foram mais visíveis os indicadores de qualidade que procuram apanhar processos, valorizando dimensões de participação e complexidade.

2 Processo de ensinagem - expressão cunhada por Pimenta e Anastasiou (2012) para designar a relação intrínseca e dependente entre ensino e aprendizagem. 
variáveis se conectem e se complementem, assumindo a complexidade do ato educativo. Trata-se de reconhecer a educação como processo interdependente e colaborativo. Assemelha-se a uma orquestra em ação, onde a harmonia e a coesão é que garantem o resultado.

\section{A QUALIDADE DO ENSINO DE GRADUAÇÃO}

De uma maneira geral, tendo em vista uma compreensão universal, a natureza da educação universitária tem sido explicitada pelo conceito da indissociabilidade do ensino, da pesquisa e da extensão. Há a compreensão de que essa condição se constitui no ponto principal da qualidade. Entretanto, a literatura internacional indica (BARNETT, 2008) que são poucos os esforços e as investigações que têm como meta compreender como a indissociabilidade é compreendida pelas comunidades epistêmicas que constituem a universidade.

Tentando avançar na compreensão desse fenômeno, tomamos esse tema como mote de uma investigação (CUNHA, 2012) que, articulada em oito eixos, procurou ouvir a literatura e os interlocutores acadêmicos sobre o conceito de indissociabilidade e como ela se manifesta na prática acadêmica. Os eixos foram: a literatura e os intelectuais que escrevem sobre a universidade; os gestores universitários; os pesquisadores seniors; os bons professores (na opinião dos pares e alunos); os estudantes; os professores universitários iniciantes; os responsáveis pela a Educação a Distância (EAD); e os representantes da sociedade que recebem os egressos da educação superior.

Os resultados do estudo são polissêmicos e múltiplos, mas algumas constâncias são possíveis de observar. A mais evidente é que o conceito de indissociabilidade do ensino, da pesquisa e da extensão é pouco aprofundado no ambiente universitário, confirmando a posição da literatura internacional. A segunda é que há, pelo menos, quatro compreensões do termo: visão epistemológica e capacidades acadêmicas; visão institucional e distribuição do conhecimento; visão metodológica nas formas de produção do conhecimento; visão política e de impacto social. De cada uma delas deriva uma compreensão de como esse conceito impacta a qualidade da educação superior. Essa nebulosidade conceitual certamente tem repercussões na gestão e nas políticas institucionais, podendo gerar diferentes indicadores de qualidade.

A partir dos dados deste estudo e instigadas pelos objetivos do Projeto Observatório/Ries (MOROSINI, 2010), construímos um instrumento usando a Escala Likert com cinco variações para apreender, com uma objetividade crescente, os indicadores de qualidade do ensino de graduação, na opinião 
de docentes universitários. Esse instrumento foi aplicado para professores e estudantes universitários de diferentes Instituições. Com base em 483 questionários respondidos e analisados estatisticamente através do Programa SPSS foi possível fazer alguns agrupamentos.

A análise quantitativa desse instrumento indicou duas grandes matrizes que redundaram em indicadores de qualidade do ensino de graduação de duas naturezas: os referenciados em produtos e os referenciados em processos.

Nesse sentido é possível apontar:

\section{Quadro 1 - Quando a Qualidade é referenciada em produtos}

\begin{tabular}{|c|c|}
\hline CATEGORIAS & INDICADORES DE QUALIDADE \\
\hline \multirow{5}{*}{$\begin{array}{l}\text { 1. Qualidade da } \\
\text { Instituição }\end{array}$} & - infraestrutura envolvendo instalações adequadas \\
\hline & - laboratórios montados e em funcionamento para os estudantes \\
\hline & - biblioteca atualizada e com acesso irrestrito \\
\hline & - assunção de processos representativos na administração universitária \\
\hline & - projeto institucional orientador das ações acadêmicas \\
\hline \multirow{4}{*}{$\begin{array}{l}\text { 2. Qualidade do } \\
\text { Corpo Docente }\end{array}$} & - titulação compatível, incluindo mestrado e doutorado \\
\hline & $\begin{array}{l}\text { - programas de formação continuada e desenvolvimento profissional para } \\
\text { os docentes na área pedagógica }\end{array}$ \\
\hline & - carreira e progressão estruturada \\
\hline & - regime de trabalho que privilegie ensino, pesquisa e extensão \\
\hline \multirow{6}{*}{$\begin{array}{l}\text { 3. Qualidade do } \\
\text { Corpo Discente }\end{array}$} & $\begin{array}{l}\text { - condições de apoio e permanência dos estudantes (auxílio a alimentação, } \\
\text { moradia, transporte) }\end{array}$ \\
\hline & $\begin{array}{l}\text { - programas de inserção na vida acadêmica, incluindo ofertas de estudos } \\
\text { compensatórios }\end{array}$ \\
\hline & - programas de intercâmbio nacionais e internacionais \\
\hline & - oportunidade de participação em programas de iniciação científica \\
\hline & $\begin{array}{l}\text { - programas de inserção social, incluindo estímulo à participação em } \\
\text { projetos solidários }\end{array}$ \\
\hline & $\begin{array}{l}\text { - programas de ação cultural fomentando a curiosidade do estudante e } \\
\text { valorizando a sua formação geral }\end{array}$ \\
\hline
\end{tabular}

Fonte: CUNHA, Maria Isabel da. Projeto Observatório da Educação Superior/RIES. CAPES/INEP/ MEC. Relatório de Pesquisa. Porto Alegre, 2011.

Quando a qualidade está referenciada em processos, refere-se a indicadores que apontam para as questões de natureza pedagógica e acadêmica, estribadas em uma concepção epistemológica compatível com a transição paradigmática vivida na contemporaneidade. Podem ser indicadores: 


\section{Quadro 2 - Quando a qualidade está referenciada em processos}

\begin{tabular}{|c|c|}
\hline CATEGORIAS & INDICADORES DE QUALIDADE \\
\hline \multirow{4}{*}{$\begin{array}{l}\text { 1. Qualidade } \\
\text { do Currículo }\end{array}$} & $\begin{array}{l}\text { - currículos inovadores que superem a tradicional organização do } \\
\text { conhecimento numa estrutura rígida e disciplinar; }\end{array}$ \\
\hline & $\begin{array}{l}\text { - explicitação do eixo teoria-prática nas propostas curriculares de forma } \\
\text { articulada e significativa (pressuposto das Diretrizes); }\end{array}$ \\
\hline & $\begin{array}{l}\text { - articulação do ensino com a pesquisa, assumindo a dúvida como princípio } \\
\text { básico dos processos de ensinar e aprender; }\end{array}$ \\
\hline & $\begin{array}{l}\text { - oferta de atividades curriculares optativas que ampliem a base cultural da } \\
\text { formação; }\end{array}$ \\
\hline \multirow{5}{*}{$\begin{array}{l}\text { 2. Práticas } \\
\text { pedagógicas }\end{array}$} & $\begin{array}{l}\text { - presença de práticas participativas que estimulem a autonomia dos } \\
\text { estudantes; }\end{array}$ \\
\hline & $\begin{array}{l}\text { - valorização de atividades autônomas que estimulem a capacidade de } \\
\text { autorregulação dos alunos; }\end{array}$ \\
\hline & $\begin{array}{l}\text { - familiarização com as linguagens tecnológicas e seus impactos nas formas } \\
\text { de produção do pensamento dos alunos; }\end{array}$ \\
\hline & $\begin{array}{l}\text { - flexibilização dos tempos/lugares da formação estimulando o contato com } \\
\text { o mundo do trabalho e da cultura; }\end{array}$ \\
\hline & $\begin{array}{l}\text { - estímulo a produção científica integradora, através de trabalhos de } \\
\text { conclusão de curso significativos e valorizados como produção integradora } \\
\text { da formação; }\end{array}$ \\
\hline \multirow{4}{*}{ 3. Avaliação } & $\begin{array}{l}\text { - estimulo à avaliação compreensiva, centrada nos objetivos e na dinâmica } \\
\text { do trabalho acadêmico; }\end{array}$ \\
\hline & $\begin{array}{l}\text { - uso de diferentes processos e múltiplos tempos na aferição da } \\
\text { aprendizagem; }\end{array}$ \\
\hline & - privilégio de aprendizagens complexas sobre a memorização; \\
\hline & $\begin{array}{l}\text { - valorização da autoria e autonomia do estudante na realização da } \\
\text { aprendizagem. }\end{array}$ \\
\hline
\end{tabular}

Fonte: CUNHA, Maria Isabel da. Projeto Observatório da Educação Superior/RIES. CAPES/INEP/ MEC. Relatório de Pesquisa. Porto Alegre, 2011.

Nos processos de avaliação de cursos e institucional, em geral, os indicadores são tomados como referentes e disponibilizados para uma determinada comunidade para que se manifeste sobre eles. A partir daí, a incidência das escolhas é que vai revelando a compreensão avaliativa dos coletivos. Ou seja, se quantifica o qualitativo.

Não há como não reconhecer que a quantidade pode ser um atributo da qualidade. Entretanto nem sempre essa relação é tão linear. Quando a qualidade se expressa em processos, os produtos se tornam relativos e a dimensão da 
qualidade exige outras formas de expressão, especialmente as que conseguem transmitir o significado da ação, o sentido que ela pode ter para alguém ou para um coletivo.

No caso da graduação, ainda que os distintos indicadores se apresentem com importância indiscutível, é inquestionável que a qualidade tem no ensino seu eixo principal. A graduação forma profissionais numa perspectiva de socialização geracional, onde os docentes são responsáveis pela proposição de conteúdos e caminhos metodológicos para a aprendizagem de seus alunos. Nessa perspectiva, o desempenho dos professores assume uma condição de especial relevo e exige uma atenção destacada. Hansen e Jackson (1996) afirmam que "apesar do extenso discurso sobre qualidade, a atividade nuclear das universidades - a docência - permanece em grande medida intacta" (p. 211). Essa posição é compartida por Antonio Nóvoa (2012) que, ao apontar as profundas mudanças no cenário da educação superior nas últimas décadas, afirma que a única dimensão que não se altera na universidade é a pedagogia.

Esses argumentos, entretanto, não significam o retorno aos tradicionais indicadores de qualidade centrados preponderantemente no professor, como tão comum aconteceu nas ultimas décadas, criando mal estar e nem sempre cumprindo objetivos meritórios. Instrumentos simplistas induziam a uma concepção de docência marcada pela tradição reprodutivista do cumprimento do programa e da burocracia acadêmica. Nem tampouco, devem reforçar os discursos que comumente culpabilizam os estudantes pelo insucesso acadêmico.

O que autores como Antonio Nóvoa (2012) e Ronald Barnett (2008) apontam é que as práticas de ensinar e aprender que se constituem no âmago do trabalho pedagógico próprio da universidade tem tido muita dificuldade para mudar. $\mathrm{E}$ é esse que deve ser o objeto da avaliação.

A avaliação institucional não deve ter os sujeitos como foco de análise e sim o trabalho que esses sujeitos estão conseguindo realizar. Trata-se, pois, de um ponto de partida que terá repercussões nos indicadores de avaliação.

Essas considerações responsabilizam a comunidade universitária pela possibilidade de avanço na qualidade da educação superior, em especial na graduação. Precisam impactar, também, as políticas públicas que definem os programas de formação para os docentes, para que valorizem e induzam inovações nesse sentido.

Mesmo considerando que a compreensão da indissociabilidade do ensino, pesquisa e extensão na universidade é ainda pouco refletida e investigada nas suas consequências na prática pedagógica, foi possível perceber, nos estudos realizados, que os indicadores de qualidade apontados por professores e estudantes 
expressam as relações entre as três funções caracterizadoras da universidade, em especial naqueles indicadores referenciados em processos. Essa condição é animadora e aponta para um movimento de ruptura com as formas tradicionais de ensinar e aprender, pelo menos na intenção dos docentes e estudantes que parecem estar interessados em avanços qualitativos, numa nova forma de compreender o conhecimento. Indicam como atributos da qualidade, o ensino em que o conhecimento é compreendido em construção e onde os estudantes atuam como protagonistas das aprendizagens, reconfigurando saberes, tempos e espaços de aprender.

O exercício de debruçar-se sobre os indicadores de qualidade do ensino de graduação constituiu-se, no contexto do Projeto Observatório, num desafio. Longe da intenção de aprisionar a complexidade dos processos de ensinar e aprender em frases simplistas, o exercício quis fazer avançar a possibilidade de uma avaliação institucional que assuma a condição de complexidade. Por essa razão, a não proposição de indicadores universais foi intencional e decorre da compreensão multireferenciada do conceito de qualidade. Essa condição, entretanto, a nosso ver, não justifica a não formulação de indicadores, mas estimula construí-los tendo em vista que eles devem ser legitimados pelas condições culturais e políticas específicas, quer de cada Instituição, quer de um conjunto delas que tenham filiações comuns. Se a formulação de indicadores se torna essencial para orientar as ações institucionais com vista à qualidade, é fundamental que esse exercício tome a proposta educativa, as condições objetivas e o contexto cultural de cada IES como referente. Trata-se de uma condição que leva em conta as dimensões universais e as condições locais. Preserve, sobretudo, a liberdade que permita, acima de tudo, educar para a cidadania, como nos estimula Sousa Santos (2000).

Esse foi o intuito do estudo e nessa direção foi que pretendemos avançar.

\section{REFERÊNCIA}

BARNETT, Ronald. Para uma transformación de la universidad: nuevas relaciones entre investigación, saber y docência. Barcelona: Octaedro, 2008.

CUNHA, Maria Isabel da. Projeto Observatório da Educação Superior/RIES. CAPES/INEP/MEC. Relatório de Pesquisa. Porto Alegre. 2011.

CUNHA, Maria Isabel da.(Org.). Qualidade da Graduação: a relação entre ensino, pesquisa e extensão e o desenvolvimento profissional docente. Araraquara: Junqueira\&Marins Editores, 2012. 
HANSEN, W.L; JACKSON, M. Total quality improvement en the classroom. Quality in Higher Education, Abringdon, v. 2, n. 3, p. 211-217, 1996.

LEI DE DIRETRIZES E BASES DA EDUCAÇÃO NACIONAL.7., Brasília: Edições Câmara, 2012. Disponível em: <http://www.riogrande. rs.gov.br/smed/wp-content/uploads/2013/04/1db_7ed.pdf >. Acesso em: 14 out. 2012.

NÓVOA, Antonio. Pedagogia Universitária: já estamos no século XXI ou ainda não? CONGRESSO IBEROAMERICANO DE DOCÊNCIA UNIVERSITÁRIA. 7., Porto, 2012. Conferência de abertura... Univ. do Porto, 2012. Disponível em: <www.fpce.up.pt/ciie/cidu>. Acesso em: 7 fev. 2014.

MOROSINI, Marilia (Coord.). Projeto observatório da educação superior. Porto Alegre: MEC/INEP/RIES, 2010.

PIMENTA, Selma; ANASTASIOU, Lea das Graças. Docência no ensino superior. São Paulo: Cortez, 2012. v. 1.

RIOS, Terezinha Azeredo. Compreender e ensinar. Por uma docência da melhor qualidade. São Paulo: Cortez, 2001.

SANTOS, Milton Por uma outra globalização: do pensamento único à consciência universal. Rio de Janeiro; São Paulo: Record, 2000.

SOUSA SANTOS, Boaventura. Crítica da razão indolente. Contra o desperdício da experiência. São Paulo: Cortez, 2000. 